\title{
ARTÍCULOS
}

\section{LOS FILMES DE ANIMACIÓN EN LOS CINES DEL MADRID DE ENTREGUERRAS (1916-1939)}

\section{Animation films in the cinemas of Madrid in the interwar period}

(1916-1939)

\author{
Gonzalo Tirado \\ Universidad Carlos III \\ gonzalo_1984aC@hotmail.com
}

Orcid: 0000-0002-1365-9248

Recibido: 27-12-2019 - Aceptado: 11-03-2020

Cómo citar este artículo/Citation:

Gonzalo Tirado, "Los filmes de animación en los cines del Madrid de entreguerras (1916-1939)", Hispania Nova, 19 (2021): 141 a 165.

DOI: https://doi.org/10.20318/hn.2021.5878
Copyright: (C) HISPANIA NOVA es una revista debidamente registrada, con ISSN 1138-7319 y Depósito Legal M 9472-1998. Los textos publicados están -si no se indica lo contrario- bajo una licencia Reconocimiento-Sin obras derivadas 3.0 España de Creative Commons. Puede copiarlos, distribuirlos y comunicarlos públicamente siempre que cite su autor y la revista y la institución que los publica y no haga con ellos obras derivadas. La licencia completa se puede consultar en: http://creativecommons.org/licenses/by-nd/3.0/es/deed.es
Resumen: En este estudio se indaga en la difusión que las producciones de cine de animación tuvieron en las salas de Madrid desde las primeras proyecciones de las que se tiene noticia, en torno a 1916, hasta el final de la Guerra Civil. El principal objetivo es constatar si los filmes de animación extranjeros llegaron a España de forma regular y también si las producciones españolas tuvieron presencia en las salas durante ese período. Las fuentes utilizadas son las secciones de cartelera que aparecen en los periódicos de la época, así como las revistas especializadas en cine y espectáculos. Partiendo de esto, se realizará un análisis cuantitativo de las carteleras de prensa, aunque dentro de una visión de conjunto, complementado todo con el análisis cualitativo de otras publicaciones del período.

Palabras clave: Cine de animación, exhibición cinematográfica, años veinte, Segunda República,
Guerra Civil.

Abstract: This study investigates the dissemination of animated film productions in Madrid's cinemas from the first projections reported, around 1916, until the end of the Spanish Civil War. The main objective is to verify whether foreign animation films arrived in Spain on a regular basis and also if Spanish productions were present in cinemas during this period. The sources used are the billboard sections that appear in the newspapers of the time, as well as the magazines specialized in cinema and shows. Based on this, a quantitative analysis of the press boards will be carried out, although within an overall vision, complemented all with the qualitative analysis of other publications of the period.

Keywords: Animated cinema, cinematographic 
exhibition, twenties, Second Republic of Spain, Spanish Civil War

\section{INTRODUCCIÓN}

Este artículo busca revelar la presencia que el cine de animación tuvo en las salas de Madrid desde la primera exhibición de la que hay constancia, en 1916, hasta el final de la Guerra Civil, el 28 de marzo de 1939. Hay muy poca información acerca de la popularidad que los filmes de animación, tanto españoles como extranjeros, tuvieron en la sociedad madrileña durante las décadas previas al franquismo, por lo que el principal objetivo es llegar a conocer el volumen de exhibición que tuvo en las salas de cine de la capital de España. La hipótesis que se plantea se basa en que los filmes de animación tuvieron una considerable difusión en los cines de Madrid durante las cuatro primeras décadas del siglo XX, por lo que, consecuentemente, también gozaría de cierta popularidad entre la población de la capital.

Para describir el estado de la cuestión de este tema, hay que hablar de un panorama bastante desolador, ya que no existen investigaciones que contengan la más mínima información del cine de animación extranjero difundido en España durante las primeras décadas del pasado siglo, encontrando apenas algunas referencias dispersas en publicaciones que tratan de forma general este período de la historia. En cambio, es posible encontrar algunos trabajos que arrojan luz sobre la difusión que pudieron tener las producciones de origen español. A lo largo del siglo XX solo se pueden citar El cine sonoro en la II República ${ }^{1}$ e Historia del dibujo animado español ${ }^{2}$, que básicamente se centran en el campo de la producción, aportando escasa información sobre los sectores de la distribución o la exhibición. En las dos últimas décadas han aparecido otras publicaciones, aunque, al igual que en las anteriores, no profundizan en la difusión en salas de cine. Obras como Cine de animación en España ${ }^{3}$ o Del Trazo al Pixel. Un recorrido por la animación española ${ }^{4}$ aportan algunos datos relevantes. Animando lo

\footnotetext{
${ }^{1}$ Román Gubern, El cine sonoro en la II República. (Barcelona:Lumen, 1977).

2 José María Candel, Historia del dibujo animado español. (Murcia: Tres Fronteras, 1993).

${ }^{3}$ Pilar Yébenes, Cine de animación en España. (Barcelona, Ariel, 2002).

${ }^{4}$ VVAA, Del Trazo al Pixel. Un recorrido por la animación española. (Barcelona, Cameo, 2015).
} 
imposible, los orígenes de la animación stop-motion (1899-1945) ${ }^{5}$, se centra en el cine de stop-motion, facilitando información inédita. También hay que destacar Cartoons: 110 años de cine de animación ${ }^{6}$, que ayuda a la comprensión de la popularidad que el cine de animación pudo tener en la sociedad española de aquellos años.

El objeto de estudio seleccionado son los filmes de dibujos o de animación stopmotion, tanto de producción española, como extranjera, que llegaron a ser exhibidos en los cines de Madrid desde las primeras proyecciones en 1916, hasta el final de la Guerra Civil en la capital. Se ha escogido la ciudad de Madrid como muestra representativa, ya que es un lugar que refleja la actividad cultural de la época.

Esta investigación tiene un carácter descriptivo e historiográfico. Para realizar este estudio, han sido utilizadas principalmente técnicas del método cuantitativo a fin de compendiar aspectos específicos sobre los filmes exhibidos en las salas de Madrid, siempre dentro de un contexto expositivo de panorámica general. Estas técnicas básicamente consisten en la cuantificación de los datos relativos al número de filmes exhibidos, así como su productora y lugar de origen. La metodología cualitativa también ha sido aplicada a la hora analizar el contexto sociocultural, y de sintetizar la información obtenida sobre los filmes anunciados en cines de Madrid, a partir de datos como el título de la obra fílmica, su productora, país de origen y la fecha y lugar de exhibición.

Hay que señalar que la información existente sobre este tema es incompleta e imprecisa, ya que prácticamente la mayor parte de los datos se obtiene de las carteleras de los cines anunciadas en la prensa de la época que facilitan una información bastante irregular, sometida a criterios de los exhibidores y de la propia prensa. En una primera fase se han intentado recopilar fuentes primarias fechadas en el período de estudio, consultando a organismos como Filmoteca Nacional, Instituto de la Cinematografía y de las Artes Visuales (ICAA), Centro Documental de la Memoria Histórica (CDMS) y Archivo General de la Administración (AGA). Paralelamente se han efectuado consultas a organizaciones vinculadas con partidos y sindicatos que, al menos durante los años de gobierno del Frente Popular, tuvieron competencias en materia cultural e industrial, como la Fundación Pablo Iglesias, la Fundación Largo Caballero, el Archivo Histórico

\footnotetext{
5 Adrián Encinas Salamanca, Animando lo imposible, los orígenes de la animación stop-motion (18991945). (Madrid, Diábolo, 2017).

${ }^{6}$ Giannalberto Bendazzi, Cartoons: 110 años de cine de animación. (Madrid, Ocho y Medio, 2003).
} 
del PCE y la Fundación Anselmo Lorenzo. La respuesta mayoritaria de estos organismos y organizaciones es la remisión a fuentes hemerográficas.

La consulta de dichas fuentes se ha realizado a través de la Hemeroteca Digital de la Biblioteca Nacional de España, la Hemeroteca Municipal de Madrid, la Biblioteca Virtual de Prensa Histórica y la Biblioteca Digital Hispánica, que han permitido examinar las revistas especializadas en cine, específicamente Cinegramas, Cine Sparta, Popular Film, Arte y Cinematografía, Cine Star, Cinelandia y Celuloide Madrileño, así como otras publicaciones que tuvieron vinculación con el sector, en concreto, Blanco y Negro, Tararí, Mi Revista, Comedia y Espectáculos. También se ha procedido al análisis de periódicos como ABC, Ahora, El Liberal, La Voz o La Libertad.

\section{LA EXHIBICIÓN DEL CINE DE ANIMACIÓN EN MADRID}

\section{6-1919: Los orígenes}

La llegada del cine de animación a España se produce en un contexto internacional enmarcado en la Primera Guerra Mundial. La neutralidad de España en dicho conflicto garantizó que no se viese alterado el lento desarrollo de la sociedad industrial y de masas, lo que también repercutiría en un aumento de la oferta cultural y de espectáculos, al menos, en entornos urbanos. En este período, la cultura adquirió una dimensión colectiva que implicó la irrupción de productos propios de la sociedad de masas de los países anglosajones, como las revistas, los espectáculos, las películas, las varietés o los deportes, que se podían contemplar en ateneos, círculos recreativos, casas de pueblo, pabellones deportivos, cines, teatros, cabarés y otros lugares de ocio ${ }^{7}$. En el caso del reciente invento del cine, la ingente cantidad de ingresos que la exhibición de producciones cinematográficas llevaba generando desde hacía algunos años, dio lugar a una estandarización de las salas de proyección y a la mejora de las redes de distribución de filmes, aumentando los intercambios transnacionales de películas.

Hay datos de exhibición de cine de animación en los cines de Madrid desde

\footnotetext{
${ }^{7}$ Matilde Eiroa, "Entre el backstage y el frontpage", en Mujeres de cine: ecos de Hollywood en España, 1914-1936, ed. por Diego Mayoral y Carlos Pérez (Madrid, Ministerio de Asuntos Exteriores y de Cooperación. Secretaría de Estado de Cooperación Internacional y para Iberoamérica: AECID, 2015), 45-46.
} 
1916, aunque es posible que hubiese proyecciones con anterioridad, ya que las primeras producciones animadas francesas o estadounidenses datan de principios de siglo, o incluso antes. Otro indicio de ello es que el primer cortometraje de dibujos animados realizado en España es El apache de Londres (1915), de autor desconocido y producido en Barcelona por Studio Films ${ }^{8}$, aunque no consta que haya sido estrenado. Realmente, solo desde el 5 de marzo de 1916 hay constancia de exhibiciones de dibujos animados, en este caso, estadounidenses. El primer filme fue Koctail, campeón de boxeo, de Bray Studios, que se estrenaría en Madrid en Royalty ${ }^{9}$. Este cine también proyectaría otras piezas de los mismos estudios a lo largo de 1916, como La hija del capitán Bum-Bum, o Koctail, el pacificador de México ${ }^{10}$.

A partir del 7 de noviembre de 1917 el Teatro de la Zarzuela programaba sesiones dedicadas exclusivamente para el público infantil, en las que se proyectaron películas de carácter instructivo o cómico y dibujos, además de sortear juguetes entre los asistentes ${ }^{11}$. Este tipo de sesiones adquirirían gran éxito años después, en el Madrid republicano.

Además de los citados cortos de Bray Studios, desde 1916 hasta 1919 aparecen anunciados en cartelera menos de una decena de filmes de dibujos animados, cuya identificación resulta muy complicada o directamente imposible, ya que no se muestran datos de la productora y el título puede deberse a una libre traducción del distribuidor o el exhibidor. La exhibición de estos cortos estadounidenses se concentró en el Royalty y en el Teatro de la Zarzuela, y ya en 1919, también en Cinema $\mathrm{X}^{12}$.

Los cortos de dibujos estadounidenses se distribuían como complementos de los largometrajes de Hollywood que se estrenaban en los cines. Realmente eran elementos de relleno que las grandes compañías suministraban como acompañamiento de sus largos de acción real. Estos cortos se adquirían por lo general, mediante contratos de distribución con pequeños estudios de animación ${ }^{13}$. Las compañías aplicaban esta

\footnotetext{
${ }^{8}$ Emilio De La Rosa, “Cine de animación en España”, en Cartoons: 110 años de cine de animación, ed. por Giannalberto Bendazzi (Madrid, Ocho y Medio, 2003) 469-508.

9 “Espectáculos”, $A B C, 05$ de marzo de 1916.

10 “Espectáculos”, $A B C, 07$ de abril de 1916 - 07 de mayo de 1916.

11 “Espectáculos”, $A B C, 07$ de noviembre de 1917.

12 "Espectáculos", $A B C, 05$ de marzo de 1916 - 04 de enero de 1919.

${ }^{13}$ Giannalberto Bendazzi, Cartoons: 110 años de..., op.cit., 183
} 
estructura de distribución, ya que el público prefería que los largometrajes estuviesen acompañados por dibujos animados y noticieros ${ }^{14}$.

Además de producciones estadounidenses, encontramos anunciados en cartelera los cortos españoles Las aventuras de Jim Trot (Joaquín Xaudaró, 1917), estrenado el 1 de marzo de 1918 en el Gran Teatro, y El Toro Fenómeno (Fernando Marco, 1917), estrenado en Royalty el 3 de junio de $1919^{15}$.

\section{La época muda de los años veinte}

La década de los años veinte supuso en Europa una etapa de reconstrucción política y económica tras el desastre de la I Guerra Mundial, mientras que, en Estados Unidos, que había sufrido menores pérdidas en el conflicto bélico, pronto registró un período de prosperidad. Los países de Europa Occidental no tardarían en sumergirse en este período denominado popularmente como "los felices años veinte", fase caracterizada culturalmente por una necesidad de evasión de la reciente guerra, convirtiéndose el hábito de acudir a todo tipo de espectáculos en un comportamiento habitual de las sociedades occidentales de entreguerras.

Aunque España no había intervenido directamente en la I Guerra Mundial, el país se encontraba a comienzos de los años veinte inmerso en una grave crisis política y social. Tras varios gobiernos cargados de inestabilidad, en septiembre de 1923, un golpe de Estado liderado por Miguel Primo de Rivera daría lugar a una dictadura militar. A pesar de este contexto político, no puede negarse que, al menos en entornos urbanos y entre las clases más favorecidas, aumentó el interés por los espectáculos de masas como el cine.

Al despegar la década de los años veinte, los cines de Madrid seguían proyectando cortos de dibujos, de complicada identificación, ya que la productora, la nacionalidad, o incluso el título, no aparecen indicados en la sección de cartelera de la prensa. Durante los primeros cuatro años de década, apenas aparecen anunciadas proyecciones de animación en las carteleras de prensa, aunque entre las escasas

\footnotetext{
14 “El metraje de los films", Popular Film, 30 de julio de 1936.

15 “Espectáculos", $A B C, 01$ de marzo de 1918 - 03 de junio de 1919.
} 
proyecciones identificadas, hay que destacar los dibujos suecos El Capitán Grogg ${ }^{16}$, creados por Victor Bergdahl, o el corto español La fórmula del Doctor Nap (Joaquín Xaudaró, 1921), proyectado el 11 de julio de $1922^{17}$.

En 1919 aparecieron en Estados Unidos las primeras series de dibujos animados cuyos protagonistas alcanzarían fama mundial: Out of the Inkwell, protagonizada por Koko y creada por los Hermanos Fleischer, así como los cortos de Félix el Gato, creados por Otto Mesmer. También adquirieron gran popularidad los dibujos Aesop's Fables, creados por Paul Terry en 1921 o, ya en 1927, la serie protagonizada por el conejo Oswald, producida por Walt Disney.

Con varios años de retraso, sería a mediados de la década cuándo la exhibición de dibujos en las salas de Madrid se convirtió en un ejemplo más de lo que estaba ocurriendo en la sociedad de masas del mundo occidental durante el período de entreguerras. En la posguerra de la Primera Guerra Mundial aumentaron el poder adquisitivo y el tiempo de ocio de la población, por lo que a lo largo de la década de los años veinte se produciría un proceso de despegue y consolidación de los denominados medios de comunicación de masas, con la aparición de un periodismo moderno, el nacimiento de la radio en 1924 y la consolidación del cine como un medio de ocio y diversión, todo ello decisivo en la concepción de una nueva significación de la información, la comunicación y el entretenimiento ${ }^{18}$.

Este contexto es el que explica que el volumen de exhibición de dibujos en los años veinte aumentase notablemente en Madrid, aunque hasta la mitad de la década no llegarían los personajes más célebres de la época muda.

A partir de 1924, la serie de dibujos animados Aesop's Fables ${ }^{19}$, de Paul Terry, llegaba a España con varios años de retraso. Según la información que aparece en las carteleras, los dibujos animados de El Gato Félix, conocido también en España como "El Gato Periquito", originarios de 1919, no llegarían a los cines de la capital hasta 1926, de la mano de la sala Royalty. Los cortos de este personaje, siendo algunos

\footnotetext{
16 “Espectáculos”, $A B C, 02$ de mayo de 1920.

17 "Espectáculos", $A B C, 11$ de julio de 1922.

${ }^{18}$ Matilde EIROA, "Entre el backstage..., op.cit., 46

19 “Espectáculos”, $A B C, 02$ de noviembre de 1924 - 31 de diciembre de 1929.
} 
sonorizados posteriormente ${ }^{20}$, se proyectarían con regularidad hasta 1932 , y de forma esporádica hasta $1942^{21}$. El personaje estrella de los Hermanos Fleischer, Koko, protagonista de la serie Out of the Inwell, conocida en España como El tintero mágico, creada en 1919, no sería visto en las pantallas madrileñas hasta 1927, proyectándose sus cortos con una inusitada frecuencia hasta 1931, convirtiéndose en el personaje más habitual hasta la llegada del sonoro ${ }^{22}$. Entre 1928 y 1929, los cortos mudos del conejo Oswald, conocido en España como "El Conejo Blas", realizados por Walt Disney y distribuidos por Universal, fueron estrenados en el Cine Callao ${ }^{23}$.

Como puede comprobarse, las principales producciones de animación estadounidense de la época muda habían consolidado su presencia en las pantallas madrileñas, aunque esto no repercutió a nivel industrial en España, ya que solo consta la exhibición de un corto español proyectado al menos en Madrid. Igualmente, salvo el citado corto sueco, no hay constancia de cine de animación de otros países, aparte de Estados Unidos, si bien es cierto que en otras partes del mundo aún no terminaba de desarrollarse una verdadera industria de animación en esta década.

Desde 1920 hasta 1926, la exhibición de cine de animación en Madrid estuvo monopolizada casi en su totalidad por la sala Royalty. Quizá debido al éxito de El Gato Félix o Koko, entre 1926 y 1929 varias salas de la capital comenzaron a anunciar proyecciones de dibujos en locales como Cinema X, Cinema Goya, Palacio de la Música, Cine Cervantes, Real Cinema, Cinema Argüelles o Cine Delicias ${ }^{24}$.

Además del descrito auge de los filmes animados en las salas madrileñas, otro indicador de la popularidad de este tipo de cine en España es la aparición de un incipiente merchandising. A lo largo de los años 20, Pat Sullivan, el propietario de la patente de la serie Felix the Cat, comenzó a comercializar artículos de este gato antropomorfo, tales como juguetes, peluches u otros productos relacionados con este personaje $\mathrm{e}^{25}$. Este tipo de industria ya estaba presente en la España de 1925, año en el que ya se puede encontrar un cómic en el que aparecía un personaje de dibujos

\footnotetext{
${ }^{20}$ Antonio Barbero, “Cinema. Resumen del año”, $A B C, 28$ de diciembre de 1930.

21 "Espectáculos", $A B C, 14$ de diciembre de 1926-06 de septiembre de 1942.

22 "Espectáculos", $A B C, 22$ de noviembre de 1927 - 04 de febrero de 1931.

23 “Espectáculos”, $A B C, 16$ de octubre de 1928 - 19 de diciembre de 1929.

24 "Espectáculos", $A B C, 19$ de octubre de 1926 - 31 de diciembre de 1929.

${ }^{25}$ Giannalberto Bendazzi, Cartoons: 110 años de..., op.cit., 55-56.
} 
animados, protagonizado por el personaje más célebre de la animación muda, Felix the Cat, que interpretaría las historietas con el nombre de "Paco Morronguis, el gato travieso" 26 .

\section{Transición del mudo al sonoro}

Al igual que ocurrió con El cantor de Jazz (Alan Crosland, 1927) para el cine en general, el estreno del corto de Disney, Steamboat Willie, en noviembre de 1928, supuso una revolución a nivel industrial y popular para el cine de animación.

Ambas obras fílmicas trajeron el sonido al cine en los albores de una crisis económica mundial, consecuencia del crack bursátil de 1929, lo que no impidió que la industria del cine continuara prosperando tras embarcarse en su nueva dimensión sonora. Podría decirse que, tras la aparición del sonido sincronizado a la imagen, el cine sufriría un fenómeno de redescubrimiento por parte del público, aumentando el interés en esta nueva forma de percibir el séptimo arte y, consecuentemente, en un aumento de la demanda, que los estudios cinematográficos no dudaron en satisfacer.

Steamboat Willie revolucionaría el paradigma del cine de animación, por lo que, desde ese momento, el público se decantó claramente por los dibujos animados sonoros. La reconversión industrial de los estudios de animación fue imparable. Disney se centraría desde 1928 en la producción de cortos cómicos sonoros protagonizados por Mickey Mouse, y en 1929 comenzaría la serie musical animada Silly Symphonies. Fleischer Studios haría lo propio con el lanzamiento en 1929 de la serie Talkartoons, que terminaría protagonizando la célebre Betty Boop. A las órdenes de Universal, Walter Lantz, creador del conejo Oswald, volvería a producir una serie de cortos con este personaje bajo el nombre de Oswald, the Lucky Rabbit. Warner Bros imitaría esta tendencia con la producción de Looney Tunes, en 1930, serie protagonizada por Bosko, así como de la serie de cortos musicales Merrie Melodies, a partir de 1931. Análogamente, Columbia emularía esta iniciativa industrial, reeditando con sonido a partir de 1929 la veterana serie Krazy Kat y estrenando en 1931 la serie Scrappy, al mando de Charles B. Mintz. Ub Iwerks, uno de los creadores del personaje Mickey Mouse, también aprovecharía el éxito del dibujo sonoro, para lanzar en 1930 la serie

\footnotetext{
${ }^{26}$ Antonio Martín, Historia del cómic español: 1875-1939. (Barcelona, Gustavo Gili, 1978).
} 
Flip the Frog. También hay que destacar otras productoras como Terrytoons, Metro Goldwyn Meyer o Van Beuren Studios.

En España, la llegada del cine sonoro se produjo en un momento de especial convulsión política, debido a la crisis derivada de la caída del régimen militar de Miguel Primo de Rivera y el proceso de cambio que supuso la proclamación de la II República y la caída de la Monarquía en 1931. No obstante, a diferencia de lo que ocurría en los años veinte, desde la aparición del sonoro, las nuevas producciones de dibujos animados llegarían a España al poco tiempo de ser estrenadas en Estados Unidos. En febrero de 1930 ya encontramos en la cartelera madrileña dibujos sonoros, como los cortos de Blas, el Conejo de la Suerte, nombre con la que se conocía en España a la serie distribuida por Universal, Oswald, the Lucky Rabbit. En abril de 1930 encontramos producciones de Walt Disney que distribuía la compañía Filmófono, como En ausencia del gato, traducción de When the cat's away, protagonizado por Mickey Mouse, o el capítulo de Silly Symphonies, El terrible toreador, ambos originales de 1929. En mayo de 1930 encontramos también dibujos sonoros de Paramount, distribuidora de Fleischer Studios $^{27}$.

La popularidad que el cine de dibujos estaba adquiriendo en España, provocó que las proyecciones de este género no se limitasen únicamente a las salas comerciales, sino que también fuesen exhibidas en otros circuitos. El 11 de abril de 1931, por ejemplo, se celebró en el Palacio de la Prensa la vigésima sesión del Cineclub Español, dedicando una sección a los dibujos animados, en la que exhibieron dibujos de El Gato Félix y Koko, así como un episodio de Silly Symphonies ${ }^{28}$. Por otro lado, ya en enero de 1930 encontramos a la venta en plena Puerta del Sol de Madrid, aparatos de exhibición doméstica destinados al entretenimiento de los niños ${ }^{29}$. Esta popularidad también se vería reflejada en la programación de sesiones dedicadas especialmente para el público infantil, con proyecciones de dibujos animados ${ }^{30}$.

\footnotetext{
27 "Espectáculos", $A B C, 05$ de febrero de 1930 - 30 de mayo de 1930.

${ }^{28}$ Román Gubern, Proyector de Luna. La Generación del 27 y el cine. (Barcelona: Anagrama, 1999).

29 "Publicidad de Cine-Kodak", $A B C, 04$ de enero de 1930.

30 “Espectáculos", $A B C, 24$ de diciembre de 1930.
} 


\section{Imagen nº 1. - Anuncio de proyector de cine de uso doméstico, incluyendo dibujos animados}

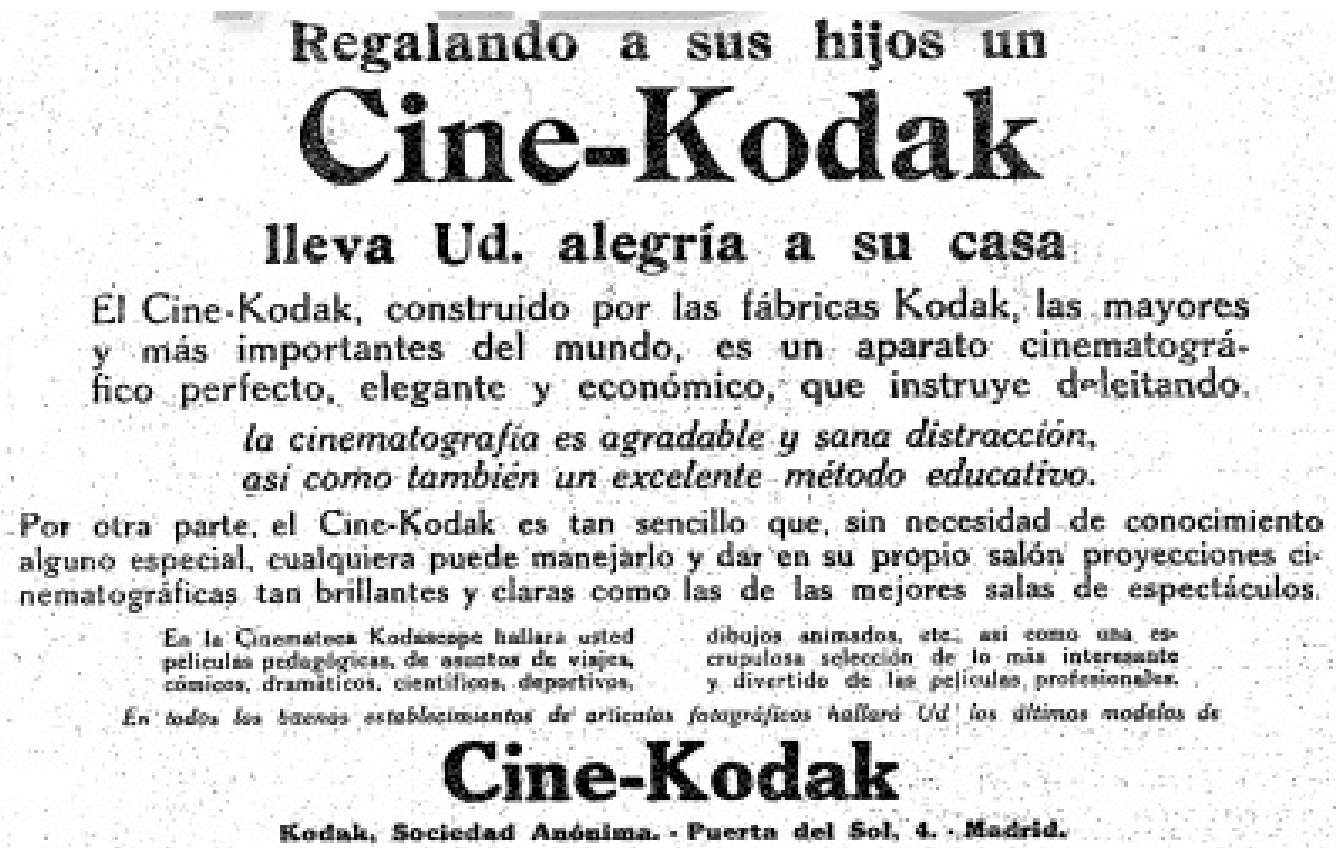

Fuente: "Publicidad de Cine-Kodak", $A B C, 04$ de enero de 1930.

De 1930 a 1932 tuvo lugar un período de transición, en el que coexistieron en los cines madrileños producciones de dibujos mudos con las novedades animadas sonoras, que acabarían imponiéndose. Prueba de ello, es que para 1931 los dibujos de Koko dejaron de proyectarse, y las proyecciones de El Gato Félix, que, aunque fueron sonorizadas, dejarían de ser habituales a partir de 1932. Mientras en la época muda, los filmes de animación estadounidenses llegaban con varios años de retraso, desde la llegada del sonoro, apenas transcurría un año o incluso menos, desde su estreno en Estados Unidos, hasta que se proyectaban en España.

Este apogeo de los dibujos animados sonoros también implicó el potente desarrollo de la industria del merchandising a nivel mundial, fenómeno iniciado en la década de los años veinte. Walt Disney haría del merchandising una industria a gran escala desde que despegó la década de los años treinta, poniendo a la venta todo tipo de artículos relacionados con el elenco animado de la compañía: cómics, pañuelos, camisetas, peines, relojes y muñecos con la imagen de Mickey Mouse y otros 
personajes $^{31}$. El fenómeno del merchandising, salvo alguna excepción, aún tardaría unos años en expandirse por España.

\section{La Segunda República}

La proclamación de la Segunda República coincidió con el impacto que tanto el cine sonoro en general, como el de los dibujos animados con sonido en particular, estaban causando entre los espectadores de medio mundo. Durante los años treinta aumentaron en España los flujos de distribución y exhibición de cine de animación, que ya existían años atrás, aunque desde aquellos años se potenciarían notablemente.

Los cortos de animación que enviaban las distribuidoras estadounidenses llegaban a España con el nombre de "complementos" o con el genérico "dibujos animados", provocando así que prácticamente no existan datos de los títulos de estos filmes de dibujos a efectos de distribución. Sí se conoce la relación de reciprocidad que cada estudio de producción de dibujos tenía con su respectiva distribuidora en Estados Unidos, por lo que se deduce que el modelo se repetía en las filiales que las compañías tenían en la España republicana.

Los cortos de Walt Disney comenzaron siendo distribuidos en el Madrid de los primeros años 30 por Filmófono ${ }^{32}$, aunque ya para 1936, los dibujos de Disney eran jurisdicción de Artistas Asociados, que ofrecería en España "dibujos de Mickey Mouse en colores" y "Silly Symphonies en colores"33. Artistas Asociados sería una filial de la compañía que desde 1932 monopolizaba la distribución de Walt Disney: United Artists.

Los filmes de Fleischer Studios eran distribuidos por Paramount, mientras que Warner Bros distribuiría los cortos de las series Looney Tunes y Merrie Melodies. Columbia tendría a la filial española Buigas \& Soler SL ${ }^{34}$. Los cortos de Terrytoons serían competencia de Hispano-Fox Films ${ }^{35}$, al igual que los filmes de Universal eran distribuidos en España por Películas Universal e Hispano American Films. Metro Goldwyn Meyer se encargaría de los dibujos producidos por estudios que tenía

\footnotetext{
${ }^{31}$ Giannalberto Bendazzi, Cartoons: 110 años de..., op.cit., 64.

32 Román Gubern, Proyector de..., op. cit., 155.

33 "Publicidad de Artistas Asociados", Arte y Cinematografia, 1 de mayo de 1936.

34 "Publicidad de Buigas y Soler SL", Arte y Cinematografía, 1 de mayo de 1936.

35 "Publicidad de Hispano-Fox Films", Arte y Cinematografia, 1 de mayo de 1936.
} 
contratados. Radio Films, filial de RKO, también distribuyó dibujos en color y en blanco y negro ${ }^{36}$. La distribuidora española UFilms anunciaba en 1936, “dibujos animados en colores", "marionetas" y "sinfonías del color" 37 entre los complementos de los largometrajes extranjeros que distribuía, centrándose en dibujos de Ub Iwerks Studios $^{38}$, mientras que otra distribuidora española, Centro Español Cinematográfico (CEC), también publicitaba distribución de dibujos animados ${ }^{39}$, ofreciendo filmes de Van Beuren Studios ${ }^{40}$.

Además se pueden encontrar otras distribuidoras en España como Distribuciones Román Solá ${ }^{41}$. Exclusivas Arajol ofrecería como complementos un filme de marionetas llamado Sin novedad en el este y dos dibujos animados titulados Mixing y los diablos y Mixing, Torero ${ }^{42}$, que parece ser que se trata de cortos de la serie distribuida por Fox Film Corporation, Mutt \& Jeff, When Hell freezes over (1926) y Mixing in Mexico (1925), respectivamente, que fueron sonorizados posteriormente, aunque no constan sus proyecciones en las carteleras madrileñas de la prensa.

En la publicidad de las distribuidoras de la época, se incluían rigurosamente los títulos de los largometrajes anunciados, incluyendo datos del director y actores, mientras que la única información sobre los filmes de animación era el número de cortos diferente de los que disponía cada compañía.

No existen datos sobre la distribución de cine de animación de otros países, aparte de Estados Unidos, ni siquiera de la propia animación española.

\footnotetext{
36 "Publicidad de Radio Films", Arte y Cinematografia, 1 de mayo de 1936.

37 "Publicidad de Ufilms", Arte y Cinematografía, 1 de mayo de 1936.

38 “Cartelera Madrileña”, $A B C$-Madrid, 15 de febrero de 1938.

39 "Publicidad de CEC", Celuloide Madrileño, 15 de febrero de 1936.

40 “Cartelera Madrileña”, $A B C$-Madrid, 18 de mayo de 1938.

41 “Publicidad de Distribuciones Román Solá", Arte y Cinematografía, 1 de mayo de 1936.

42 "Publicidad de Exclusivas Arajol”, Arte y Cinematografía, 1 de mayo de 1936.
} 


\section{Imagen n². - Fragmento de anuncio publicitario de la distribuidora UFilms}

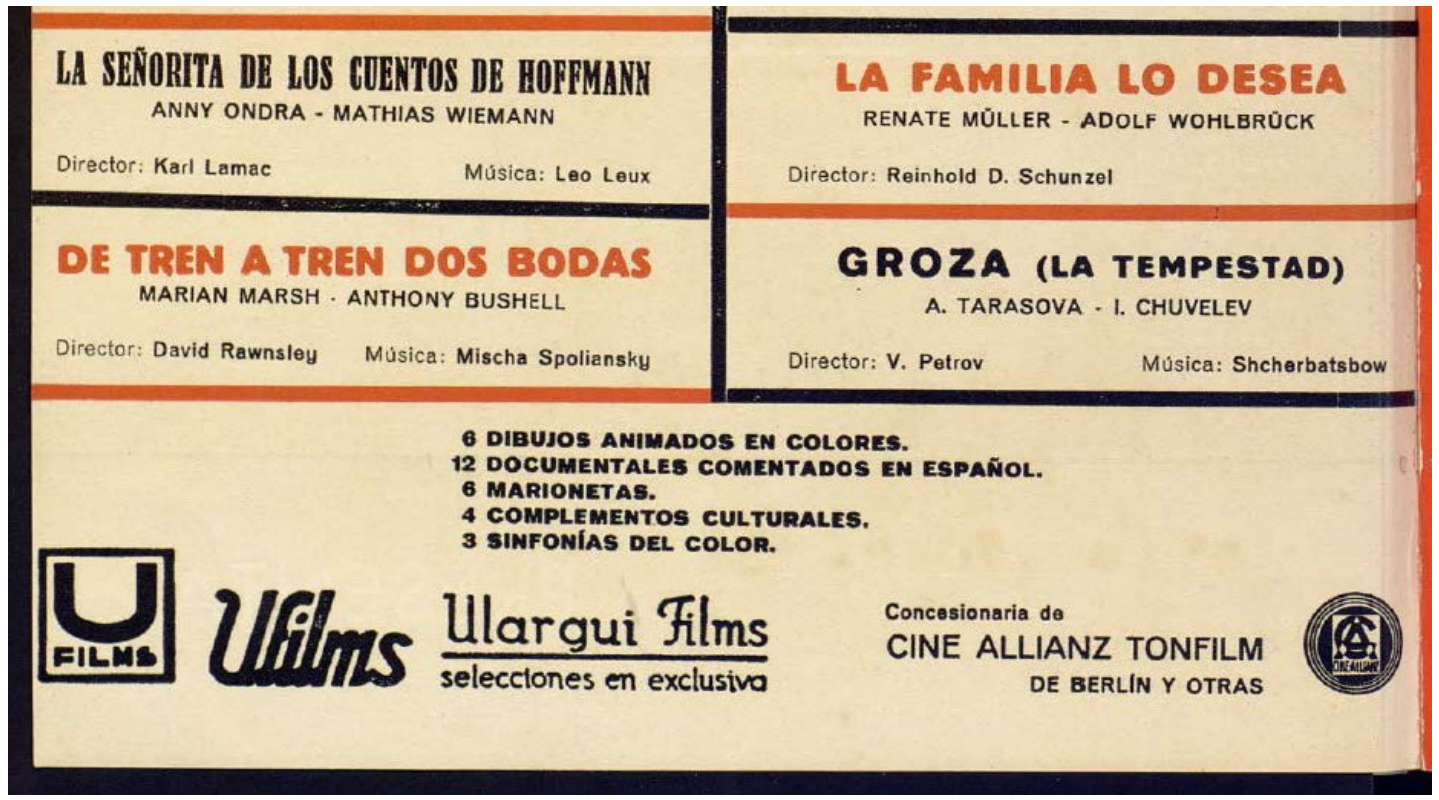

Fuente: "Publicidad de Ufilms", Arte y Cinematografia, 1 de mayo de 1936.

A diferencia del campo de la distribución, las fuentes, principalmente hemerográficas, ofrecen una mayor información sobre el campo de la exhibición en cines. Desde la instauración de la Segunda República, hasta el inicio de la Guerra Civil, el cine de animación fue aumentando su cuota de pantalla. El 14 de abril de 1931, día en que se celebraba la proclamación de la República en las calles de la capital, hasta cuatro cines tenían programados cortos protagonizados por Mickey Mouse, haciéndose evidente la omnipresencia de este ratón antropomorfo en las salas madrileñas, al igual que sucedió con las Silly Symphonies de Walt Disney, como llevaba ocurriendo desde 1930. Walt Disney, estrenaba en 1932 su primer corto animado en color, titulado Flowers and trees, que a finales de diciembre de ese mismo año se estrenó en Actualidades, llegando por primera vez a Madrid los dibujos en color ${ }^{43}$.

Los dibujos sonoros de Fleischer Studios, también alcanzarían un gran volumen de exhibición. A comienzos de 1933, ya se puede encontrar en cartelera un corto de la serie Talkartoons, concretamente Swim or Sunk (1932), llamado en España ¡Nada o ahógate!, protagonizado por Betty Boop, Bimbo y Koko. Tanto los de Talkartoons, como los de Betty Boop, se proyectarían constantemente durante los siguientes años en

43 “Cartelera Madrileña”, $A B C, 14$ de abril de 1931- 07 de febrero de 1936. 
el Madrid republicano. La serie Popeye, el marino, que se estrenó en Estados Unidos en 1933, llegaría en octubre de 1934, gozando de proyecciones permanentes durante los siguientes años ${ }^{44}$.

Los dibujos del estudio de Leon Schlesinger, se exhibieron como complemento de las películas de Warner Bros, encontrándose alguna referencia en las carteleras de la época que anunciaba dibujos protagonizados por Bosko, ya en $1934^{45}$. Aunque apenas hay datos, también hay constancia de filmes de dibujos distribuidos por Columbia, como el corto Bunnies and Bonnets (1933), perteneciente a la serie Krazy Kat, que ya a finales de 1933 aparecía en el Cine Panorama ${ }^{46}$.

Universal continuaría presente en el panorama de los dibujos sonoros desde 1930, gracias a la serie de El Conejo Blas, traducción libre de la original Oswald the Lucky Rabbit ${ }^{47}$. La serie Flip the Frog, creada en los estudios de Ub Iwerks, también formaría parte del repertorio de dibujos sonoros en el Madrid republicano, encontrándose sus primeras proyecciones en abril de 1931, con cortos como Flip, campeón de boxeo, manteniéndose en las carteleras aún en $1935^{48}$.

Aunque la producción de animación de los países europeos fue muy exigua, se puede encontrar alguna referencia en la cartelera capitalina. Del ruso Ladislas Starevitch, afincado en Francia desde 1919, realizador de animación "de marionetas", hay constancia de varios estrenos de sus obras. En abril de 1934, comenzaría a exhibirse en el Cine Callao uno de los cortos de la serie Fetiche, que tendría tal éxito que se asentaría en las salas madrileñas durante ese año y el siguiente, siendo publicitado como el complemento de más popularidad de ese año ${ }^{49}$. A comienzos de 1935 se anunció la proyección en el Cine Velussia del corto El león envejecido, traducción de Le lion devenu vieux (1932) que contaría con más exhibiciones a lo largo de 1935. También a comienzos de este año se anunció el corto de Starevitch El león y el mocito ${ }^{50}$.

También de animación stop-motion (o "de marionetas", como se llamaba en la

\footnotetext{
44 “Cartelera Madrileña”, $A B C, 23$ de febrero de 1933- 06 de febrero de 1936.

45 “Cartelera Madrileña”, $A B C, 28$ de octubre de 1934.

46 "Cartelera Madrileña”, $A B C, 23$ de diciembre de 1933.

47 “Espectáculos", $A B C, 05$ de febrero de 1930 - 15 de diciembre de 1935.

48 “Cartelera Madrileña”, $A B C, 19$ de abril de 1931- 16 de mayo de 1935.

49 “Cartelera Madrileña”, $A B C, 29$ de abril de 1934.

50 “Cartelera Madrileña”, $A B C, 28$ de abril de 1934 - 24 de noviembre de 1935.
} 
época), es el único filme de animación proveniente de la URSS del que hay constancia que haya sido exhibido en salas comerciales de Madrid en aquellos años. Se trata de $E l$ Nuevo Gulliver, realizado por Alexander Ptushko en 1935 y estrenado en español a finales de ese mismo año, obteniendo tal popularidad que, al igual que las obras de Starevitch, sus proyecciones se prolongarían semanas y semanas ${ }^{51}$. Hay que destacar que se trata del primer largo de animación estrenado en España desde la invención del cinematógrafo.

El primer filme español de animación estrenado en salas comerciales desde los años veinte, fue Francisca, la mujer fatal (Ricardo García "K-Hito", 1934) producido por la SEDA y permaneciendo la primera semana de abril de 1934 en el Cine Velussia $^{52}$. Posiblemente atraídos por el éxito que estaban teniendo las obras de animación de marionetas de Starevitch y Putshko en España, los empresarios de la exhibición decidieron apostar también por producciones españolas de ese estilo. Una de las obras pioneras de este tipo de animación, Arte, amor y estacazos (Pablo Antonio Béjar y Miguel Ramos, 1934), fue estrenada en el Cine Rialto el 13 de enero de $1936^{53}$, como complemento de la película de ficción La hija del penal (Eduardo García Maroto, 1936) ${ }^{54}$, aunque ya en junio de 1934 se realizó un pase privado para la crítica $^{55}$. Conviene aclarar que desde 1932 hasta el comienzo de la Guerra Civil, se produjeron un total de 18 cortos animados en España, trece de dibujos animados y cinco de animación stop-motion, pero en el período descrito solo hay constancia de exhibiciones de los dos casos citados, encontrándose alguna proyección más durante la Guerra Civil, como se explicará en el apartado correspondiente.

Desde 1931 a 1936 la cantidad de salas que ofrecían cine de animación en Madrid, ya sea de forma regular o esporádica, era enorme. Monumental, Royalty, Real Cinema, Cinema X, Actualidades, Astur Cinema, Astoria, Panorama, Tivoli, Velussia, Calatravas, Rialto y otras salas se encargaban de acercar este género al espectador madrileño ${ }^{56}$.

\footnotetext{
51 “Cartelera Madrileña”, $A B C, 24$ de diciembre de 1935 - 07 de febrero de 1936.

52 "Cartelera madrileña", $A B C, 1-7$ de abril de 1934.

53 “Cartelera madrileña”, $A B C, 12$ de enero de 1936.

${ }^{54}$ Antonio Guzmán Merino, "La semana cinematográfica”, Cinegramas, 19 de enero de 1936.

${ }^{55}$ Alfredo Miralles, "Una película española de muñecos", $A B C, 03$ de junio de 1934.

56 “Cartelera Madrileña”, $A B C, 14$ de abril de 1931 - 15 de febrero de 1936.
} 
En verano de 1934 comenzarían a organizarse las sesiones conocidas como "Semana Walt Disney" en cines como Actualidades o Tivoli, en las que se proyectaban varios cortos de esta compañía y se entregaban obsequios a los niños, como juguetes, balones $^{57}$ o $\operatorname{caretas}^{58}$.

Lo mismo ocurriría con los dibujos de Paramount. En verano de 1935, aparecen anunciadas en el cine Actualidades las sesiones denominadas "Semana de Betty Boop", orientadas al público femenino e infantil, que consistían en proyecciones de varios cortos de este personaje en las que se sorteaban muñecas de Betty Boop ${ }^{59}$. Tanto en estas semanas de Walt Disney, como en las de Betty Boop, esos regalos en ocasiones se repartirían a todos los asistentes y en otras, se obtendrían mediante sorteo.

Debido a que prácticamente todos los datos acerca de la exhibición de cine de animación de Madrid solo pueden extraerse de las secciones de la cartelera de los periódicos de la época, la información puede contener inexactitudes, ya que, estas producciones de animación tenían una valoración menor que los largometrajes a los que acompañaban. Muchas veces estos filmes no eran anunciados en la cartelera o lo eran bajo el genérico nombre de "dibujos animados". Cuando eran anunciados, al ser traducidos, podían ser interpretados a criterio del exhibidor o el distribuidor, llegando incluso a modificar los nombres de los protagonistas. Sobre todo, a partir de la llegada del sonoro, los circuitos de exhibición se multiplican, proyectándose películas en cineclubs o incluso llegando a la exhibición doméstica, por lo que, en ocasiones, fechas referentes a estrenos o períodos en cartelera pueden ser incorrectos, principalmente para las producciones importadas. En el caso de los filmes españoles, no sería descartable que algunos de los cortos, hubiesen sido exhibidos en proyecciones privadas.

Además de la presencia constante y diversa del cine de animación en las salas madrileñas, hay que mencionar que, durante los años previos a la guerra, se produjo una explosión de merchandising relacionado con estos filmes en España, por lo que aumentó la producción de cómics, historietas en prensa, almanaques, juguetes y otros artículos.

\footnotetext{
57 “Cartelera Madrileña”, Ahora, 25 de febrero de 1936.

58 “Guía del espectador”, $A B C, 02$ de junio de 1934.

59 “Cartelera Madrileña”, $A B C, 27$ de agosto de 1935
} 


\section{Primavera de 1936}

En los meses previos a la Guerra Civil, encontramos una gran oferta de filmes de animación en los cines de Madrid, bien como complementos de los largometrajes de Hollywood o bien proyectados en las ya citadas "jornadas infantiles". Durante los meses previos al conflicto, estas sesiones de los jueves por la tarde eran muy populares, cuando además de ver una película cómica de Charles Chaplin, Oliver y Hardy o La Pandilla, también se proyectaban dibujos animados en los que aparecían personajes como Mickey Mouse, Pluto, Pato Donald, La Vaca Clarabella, El Caballo Horacio o Minnie Mouse, por parte de Walt Disney, o Popeye y Betty Boop, de Fleischer Studios ${ }^{60}$ y como ya se indicó, terminaban con un sorteo de juguetes entre el público. En ocasiones, el público lo formaban alumnos de las escuelas municipales y los establecimientos benéficos ${ }^{61}$. Igualmente, continuaban en boga las "Semanas Walt Disney", así como las "Semanas de Betty Boop" o "Semanas Paramount". Como dato anecdótico, cabe añadir que llegaron a realizarse proyecciones $3 \mathrm{D}$, como la organizada por el cine Actualidades en abril de $1936^{62}$.

Imagen n⿳3. - Fotografía de un "jueves infantil”.

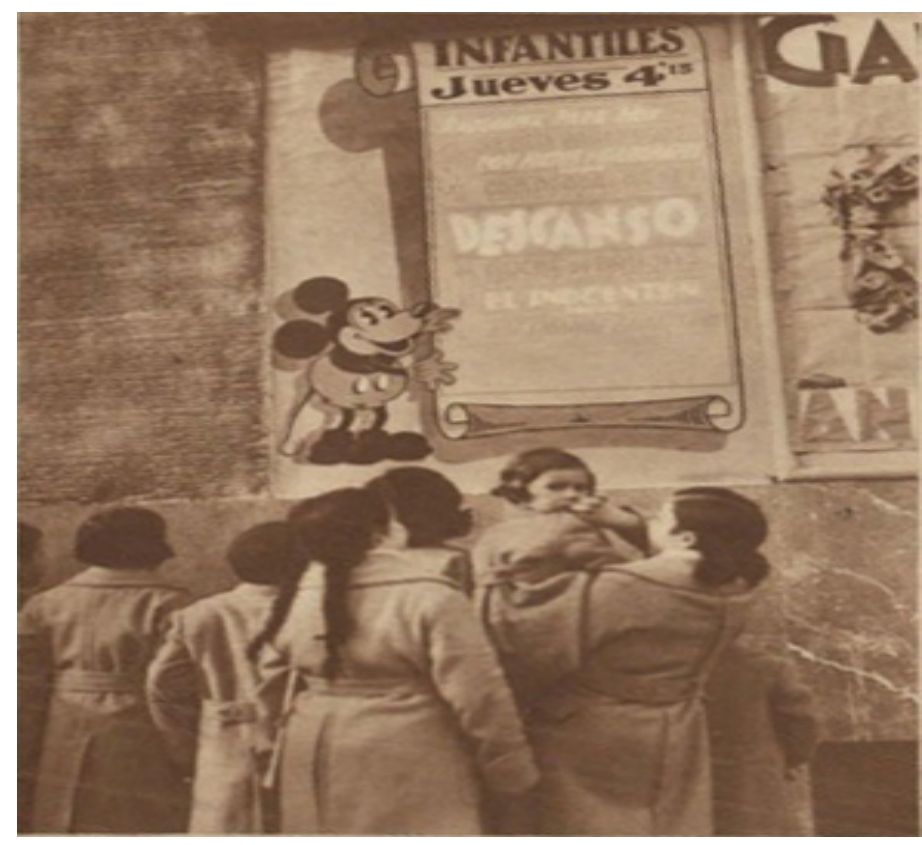

\footnotetext{
${ }^{60}$ Julio Romano, "El cine ha convertido en realidad los sueños de los niños, porque todos quieren ser como Spanky, el pequeñuelo que hace lo que le da la gana", Cinegramas, 01 de marzo de 1936.

61 "Publicidad del Día del Cinema-Año IV", Popular Film, 11 de junio de 1936.

62 “Anuncio del cine Actualidades”, Cinegramas, 12 de abril de 1936.
} 
Fuente: Julio Romano, $A B C, 01$ de marzo de 1936.

El período entre febrero y julio de 1936 concentra un gran número de salas que anunciaban sus proyecciones de cine de animación en la cartelera. En esa etapa se cuentan unos 46-48 cines en la capital ${ }^{63}$, de ellos, hasta seis anunciaban cine de animación, cifra que probablemente sea inferior a la cantidad real.

En los meses previos a la Guerra Civil, las proyecciones predominantes eran los cortos de dibujos animados estadounidenses, encontrándose más de cincuenta títulos diferentes. Fleischer Studios fue la productora que más filmes proyectó, con series como Popeye, the Sailor, Betty Boop o Color Classics. Prácticamente la misma presencia en cines tuvo Walt Disney, con sus cortos de Mickey Mouse y, sobre todo, de Silly Symphonies. Aunque en menor cantidad, se encuentran proyecciones de filmes de series de Columbia, como Krazy Kat o Color Rhapsody, así como de Ub Iwerks Studios, con la serie ComiColors Cartoons. Igualmente, hay constancia de exhibición de cortos de las series Happy Harmonies, de Metro Goldwyn Meyer, Rainbow Parade, de Van Beuren Studios, Merrie Melodies, de Warner Bros y Oswald The Lucky Rabbit, de Universal. También Terrytoons, que ofreció filmes de Farmer Al Falfa, entre otras producciones $^{64}$.

Además de las producciones de Estados Unidos, en la primavera de 1936 no hay constancia en las carteleras de cine de animación de otros países, a excepción del largometraje soviético de stop-motion, El Nuevo Gulliver, que llevaba proyectándose con éxito desde tiempo atrás ${ }^{65}$.

\section{Guerra Civil}

El inicio de la guerra provocó un descenso del número de salas de cine en funcionamiento en la capital, reduciéndose casi a la mitad los días posteriores a la sublevación ${ }^{66}$ y llegando a haber solo tres salas abiertas durante los días más duros de la

\footnotetext{
63 “Cartelera Madrileña”, Ahora, 16 de febrero de 1936 - 17 de julio de 1936.

${ }^{64}$ Secciones de la cartelera de cines de Madrid de los diarios Ahora, ABC, La Libertad, El Liberal y La Voz, entre el 16 de febrero y el 17 de julio de 1936.

${ }^{65}$ ibidem.

66 “Cartelera Madrileña”, Ahora, 22 de julio de 1936.
} 
denominada Batalla de Madrid, en noviembre de $1936^{67}$. No obstante, a partir de 1937, las salas volvían gradualmente a funcionar con relativa normalidad, llegando a aparecer hasta 34 anunciadas en la cartelera de prensa a finales de marzo de $1939^{68}$. Según la cartelera aparecida en la prensa de la época, el cine de animación continuó presente en las pantallas madrileñas durante todo el conflicto bélico, siendo Actualidades el cine que concentró un mayor número de proyecciones ${ }^{69}$.

\section{Imagen $\mathbf{n}^{\circ} 4$. - Publicidad del cine Actualidades anunciando proyecciones del sindicato anarquista SUICEP, junto a un dibujo de Mickey Mouse}

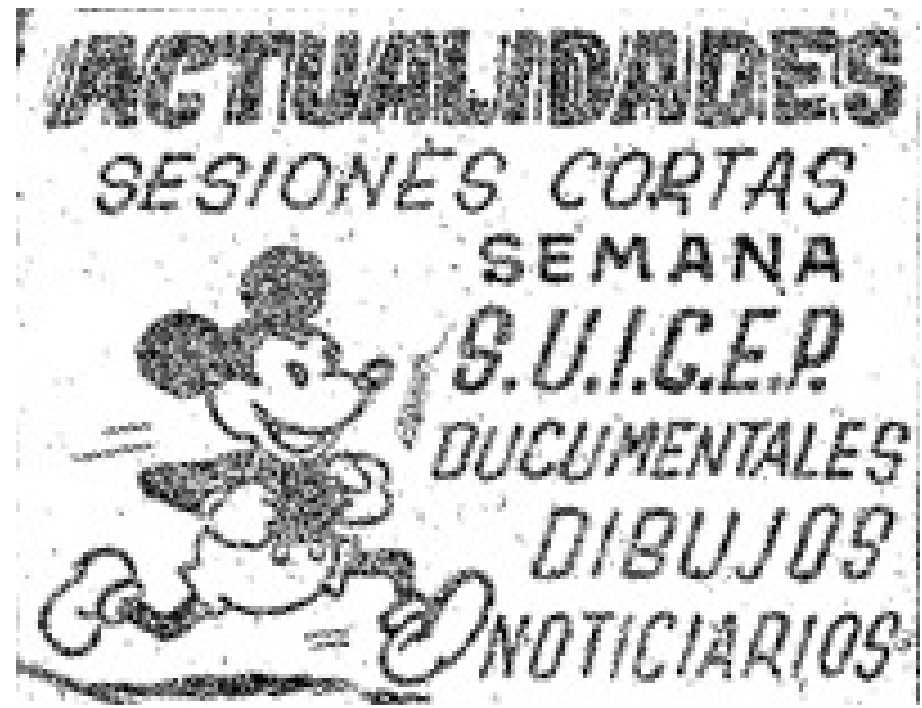

Fuente: "Publicidad del cine Actualidades", $A B C, 20$ de febrero de 1938.

La guerra, sin embargo, no fue un obstáculo para que el cine de animación continuase siendo proyectado en la capital. Además de los cortos exhibidos como complementos, continuarían organizándose las semanas monográficas dedicadas a Walt Disney o a los dibujos de Fleischer Studios. También se realizarían sesiones monográficas de otras compañías, como la "Semana de Warner Bros", en la que se proyectaron varios cortos de dibujos de dicha compañía. Análogamente, se celebró una "Semana Ufilms", con proyecciones de varios cortos de Ub Iwerks Studios, así como

\footnotetext{
67 “Cartelera Madrileña”, $A B C$-Madrid, 10 de noviembre de 1936.

68 "Espectáculos", La Voz, 27 de marzo de 1939.

${ }^{69}$ Secciones de la cartelera de cines de Madrid de los diarios Ahora, ABC y La Libertad, entre el 18 de julio de 1936 y el 27 de marzo de 1939.
} 
una "Semana CEC", en la que se exhibieron cortos de Van Beuren Studios ${ }^{70}$.

En las carteleras aparecidas en la prensa madrileña a lo largo de la Guerra Civil ha sido posible identificar al menos 102 cortos diferentes de dibujos animados estadounidenses, siendo Walt Disney la compañía de la que se encuentran más títulos anunciados, principalmente de los cortos cómicos de Mickey Mouse, aunque también las Silly Symphonies. A pesar de que Fleischer Studios cuenta con menos títulos exhibidos, estos aparecen anunciados durante más semanas que los de Walt Disney, sobre todo los de Popeye, the sailor y Betty Boop, sin olvidar algunas proyecciones de los filmes de la serie Color Classics ${ }^{71}$.

Por detrás de estas dos grandes compañías, también constan en cartelera otros cortos de dibujos realizados en estudios estadounidenses, como los de las series Whillie Whopper y ComiColors, de Ub Iwerks Studios, Looney Tunes y Merrie Melodies de Warner Bros, Tom \& Jerry y Rainbow Parade de Van Beuren Studios y Happy Harmonies de Metro Goldwyn Meyer. Columbia estuvo presente en las pantallas de Madrid con las series Scrappy, Krazy Kat, Color Rhapsody y otros cortos. Aunque no aparecen en cartelera proyecciones de cortos de Terrytoons o Universal, como sí sucedía las semanas previas al inicio de la guerra, no es descartable que se realizasen exhibiciones de estas compañías ${ }^{72}$.

Además de estos 102 filmes de dibujos animados norteamericanos, en el Madrid de la Guerra Civil también se encuentran las escasas proyecciones del corto español de animación stop-motion titulado Españoladas (1935), dirigido por Salvador Gijón, así como del largometraje soviético El Nuevo Gulliver. Debe aclararse que, aunque hay constancia de tres cortos de animación producidos en total en ambas zonas beligerantes durante la Guerra Civil, dos de stop-motion y uno de dibujos, no consta que hayan sido proyectados en las salas de Madrid. De los 104 filmes exhibidos, la mayoría fueron producidos entre 1934 y 1935, no encontrándose filme alguno realizado entre 1937 y $1939^{73}$.

\footnotetext{
${ }^{70}$ Ibidem

${ }^{71}$ Ibídem.

72 Secciones de la cartelera de cines de Madrid de los diarios Ahora, ABC y La Libertad, entre el 18 de julio de 1936 y el 27 de marzo de 1939.

${ }^{73}$ Ibídem
} 


\section{CONCLUSIONES}

En conclusión, las pantallas españolas, y en concreto, las madrileñas, fueron un reflejo del contexto creativo e industrial del cine de animación durante las primeras décadas del siglo XX, llegando a los cines de la capital española los filmes más exitosos en los países occidentales, que provenían mayoritariamente de Estados Unidos, encontrándose también una tímida réplica de producciones españolas.

Resulta complicado establecer, al menos a nivel cuantitativo, la relevancia que tuvo el cine de animación en la población madrileña durante el período de estudio, ya que directamente no existen datos relativos a la afluencia de público a las salas, tales como la recaudación en taquilla o el número de espectadores. No obstante, si se analizan conjuntamente la cartelera de la época, junto con los exiguos datos que hay acerca de la presencia de este tipo de cine sobre producciones culturales como el merchandising relacionado, sería posible conocer unos indicadores relativos a este fenómeno, todo ello, dentro de un marco comparativo con otros países.

El despertar industrial del cine de animación durante la década de 1910 dejó su impronta en Madrid con la llegada de varias producciones estadounidenses, animando también a que algunos creadores españoles se adentrasen en la producción de este tipo de cine. El cine de animación en Estados Unidos ya había alcanzado un gran nivel de distribución, exportándose sin dificultad, junto con otros filmes de acción real, en detrimento de las producciones europeas, cuya industria cinematográfica se encontraba gravemente afectada por las vicisitudes de la I Guerra Mundial. Ya en esta década, las pantallas de Madrid serían un ejemplo de los inicios de la omnipresencia del cine estadounidense. Aunque no hay constancia de producción de merchandising $o$ repercusión iconográfica de cine de animación en el Madrid de esta década, el hecho de que comenzasen a programarse sesiones de dibujos dirigidas al público infantil, podría implicar que ya dejó cierta impronta en algunos sectores de la población, aunque, como ocurría en Estados Unidos y otros países, el cine de animación aún no se había convertido en un tipo de cine muy popular.

Sería a lo largo de la década de los años veinte, cuando los filmes de dibujos animados irían adquiriendo una considerable popularidad entre la población madrileña. El personaje conocido como El Gato Félix, creado en 1919 en Estados Unidos, supondrá el origen del "star system animado", dando lugar, paralelamente, al fenómeno del merchandising relacionado con los personajes de dibujos, tanto en Estados Unidos, 
como en Europa. Aunque a lo largo de la década de los años 20 los filmes animados irían llegando de forma paulatina y con varios años de retraso a las salas de la capital, a finales de la década, personajes como El Gato Félix, El Conejo Blas o Koko, se mantuvieron de forma habitual en las carteleras madrileñas, encontrándose, además, algunas muestras de merchandising relacionado en España, como cómics y otros artículos. Esto demuestra que a finales de los años veinte, en plena dictadura de Miguel Primo de Rivera, la capital de España intentaba alcanzar el ritmo de vida social y cultural que se estaba viviendo en otras grandes ciudades en el período de entreguerras.

El estreno en Estados Unidos del corto de Walt Disney Steamboat Willie en noviembre de 1928, supuso un punto de inflexión en la industria del cine de animación a nivel mundial. Desde ese momento, la animación se convertirá en un negocio notablemente rentable, originándose una fuerte competencia entre distintos estudios estadounidenses y dando lugar al surgimiento de estas producciones en otros países del mundo. En Madrid, este fenómeno se ve reflejado al comprobar que, tras el impacto de la llegada del cine de animación sonoro, las producciones extranjeras comenzaron a llegar de forma masiva, regular y puntual a las salas madrileñas.

A lo largo de la II República en los cines de Madrid proliferaron dibujos animados de más de una decena de compañías estadounidenses, además de algunas notables producciones de cine de stop-motion de origen francés o soviético. Este apogeo del cine de animación sonoro provocaría la correspondiente respuesta española, aunque discreta, como consta en las carteleras de la época. A lo largo de la primera mitad de los años treinta, puede considerarse que Madrid se convierte en una ciudad plenamente integrada a nivel cultural en la sociedad de masas característica del período de entreguerras. Prueba de ello es la presencia del cine de animación extranjero en la capital, cuyas proyecciones ya eran tan habituales en los cines como el resto de películas, a la par que se desarrollaba en la España republicana toda una industria diversificada de productos relacionados con estos filmes, tales como cómics, juguetes, almanaques y otros artículos. También aumentó el interés de la prensa por este tipo de cine. Todos estos factores son indicadores de la notable relevancia que el cine de animación iba adquiriendo en la población española.

Resulta interesante comprobar cómo el inicio de la Guerra Civil no supuso la interrupción de las proyecciones de animación en Madrid, sino que continuaron exhibiéndose con la relativa normalidad que corresponde a una ciudad inmersa en un 
conflicto bélico. El estudio de la cartelera de los cines de la época, sumada a aspectos de carácter cualitativo, como la presencia iconográfica de este tipo de cine en cómics, u otro tipo de manifestaciones culturales, han permitido un análisis más profundo de la recepción que este tipo de cine pudo haber tenido en Madrid. Gracias a la síntesis de toda esta información, es posible establecer una base para nuevos estudios de índole sociocultural relacionados con la sociedad española de dicha época.

En resumen, la oferta de cine de animación en Madrid fue bastante considerable, haciendo de este género cinematográfico un espectáculo familiar y cotidiano en la vida de la población madrileña de aquellas décadas.

\section{BIBLIOGRAFÍA}

Bendazzi, Giannalberto. Cartoons: 110 años de cine de animación, Madrid: Ocho y Medio, 2003.

Candel, José María. Historia del dibujo animado español. Murcia: Tres Fronteras, 1993. De la Rosa, Emilio. "Cine de animación en España”, en Cartoons: 110 años de cine de animación, editado por Giannalberto Bendazzi, 469-508. Madrid: Ocho y Medio, 2003.

Eiroa, Matilde. "Entre el backstage y el frontpage", en Mujeres de cine: ecos de Hollywood en España, 1914-1936, editado por Diego Mayoral y Carlos Pérez, 36-54. Madrid: Ministerio de Asuntos Exteriores y de Cooperación. Secretaría de Estado de Cooperación Internacional y para Iberoamérica: AECID, 2015.

Encinas Salamanca, Adrián. Animando lo imposible, los orígenes de la animación stopmotion (1899-1945). Madrid: Diábolo, 2017.

Martín, Antonio. Historia del cómic español: 1875-1939. Barcelona: Gustavo Gili, 1978.

Gubern, Román. El cine sonoro en la II República (1929-1936). Barcelona: Lumen, 1977.

Gubern, Román. Proyector de Luna. La Generación del 27 y el cine. Barcelona: Anagrama, 1999.

VVAA. Del trazo al pixel. Un recorrido por la animación española. Barcelona: Cameo, 2015.

Yébenes, Pilar. Cine de animación en España. Barcelona: Ariel, 2002.

\section{FUENTES HEMEROGRÁFICAS}

ABC-Madrid, ejemplares consultados desde el 05 de marzo de 1916 hasta el 28 de marzo de 1939.

Ahora, ejemplares consultados desde el 16 de febrero de 1936 hasta el 05 de diciembre 
de 1938.

Arte y Cinematografía, ejemplares consultados desde el 01 de marzo de 1936 hasta el 01 de mayo de 1936.

Blanco y Negro, ejemplares consultados desde el 05 de abril de 1936 hasta el 03 de mayo de 1936.

Celuloide Madrileño, ejemplares consultados desde el 15 de febrero de 1936 hasta el 01 de mayo de 1936.

Cine Sparta, ejemplares consultados desde el 28 de marzo de 1936 hasta el 30 de abril de 1936.

Cinegramas, ejemplares consultados desde el 04 de agosto de 1935 hasta el 19 de julio de 1936.

El Liberal, 17 de febrero de 1936.

La Libertad, ejemplares consultados desde el 05 de marzo de 1938 hasta el 11 de febrero de 1939.

La Vanguardia, ejemplares consultados desde el 05 de febrero de 1918 hasta el 15 de marzo de 1939.

La Voz, 27 de marzo de 1939

Mi Revista, ejemplares consultados desde el 15 de octubre de 1936 hasta el 01 de diciembre de 1938.

Popular Film, ejemplares consultados desde el 2 de febrero de 1936 hasta el 01 de abril de 1937. 